\title{
Technology Procurement in Election Systems
}

\author{
David A. Bennett
}

\begin{abstract}
Election administrators have a variety of responsibilities that extend beyond the management of election day. They are also responsible for the procurement of the voting systems that will be used by the public. There are a variety of approaches that can be utilized to make this process more efficient. Focusing on Florida, the author discusses the process that was utilized to innovate technology procurement and provides recommendations for the profession to close the information gap that exists between procurement experts, election officials, and vendors.
\end{abstract}

Keywords Technology $\bullet$ Procurement $\bullet$ Vendors $\bullet$ Coordination

- Collaboration

I am the financial officer and corporate treasurer for VR Systems, Inc., an employee-owned company in the election business that sells electronic pollbooks and voter registration software. This software generates and holds voter registration data for use by local and state election officials during the voting process. In my role as financial officer and treasurer, I am responsible for financial forecasting, accounting, human resources, and

D. A. Bennett $(\bowtie)$

VR Systems, Inc., Tallahassee, FL, USA

e-mail: dbennett@vrsystems.com

(C) The Author(s) 2019

M. Brown et al. (eds.), The Future of Election Administration, Elections, Voting, Technology, https://doi.org/10.1007/978-3-030-18541-1_24 
other related functions. I am also involved in negotiating contracts for the acquisition and use of VR Systems technology and services, and other related relationships with local governments and other vendors in the election policy space.

My experience with technology procurement comes from more than 17 years of service in Florida state government with an emphasis on government procurement and contracting. There, I was responsible for overseeing large-scale projects involving the acquisition and deployment of information technology, hardware, and software across multiple government agencies. The end users were government agencies and, through those agencies, the general public.

\section{Illustration of Technology Procurement}

As one example, I worked for approximately three years on an intergovernmental contract for a statewide services portal for the State of Florida, now known as MyFlorida. This encompassed creating and implementing one of the first (if not the first) electronic government procurement systems in the nation. The purpose of MyFlorida was to create a seamless electronic experience for the general public when accessing Florida government agencies for state and local transactions, and to create a centralized electronic state purchasing process through the portal called MyFloridaMarketplace. An easy example of the part of this portal that faces the general public is the tag line "MyFlorida.Gov" that you see today on Florida license plates.

The MyFloridaMarketplace experience illustrates several points that can help election administrators in their purchasing process, particularly related to technology. The scale of this project was quite large and the concept was innovative at the time. Those of us involved were working on what we called the "bleeding edge." The procurement and installation of the technology necessary to bring about MyFloridaMarketplace required cross-functional teams that included representatives from every agency and in a range of specialties. For this process we pulled together experts in accounting, procurement, IT, and other subject matter experts (SMEs).

All the particulars were negotiated around the state's standard accounting system, called Florida Accounting Information Resource (FLAIR). The MyFloridaMarketplace steering committee involved political representatives from both houses of the Florida legislature and the governor's budget office, among others. 
When implementation began, what we learned was that every state agency operated their own "homegrown" accounting system, and built their accounting system around their processes and missions. In practical terms, what this meant was that although FLAIR seemed to be a uniform state accounting system, it was supported by data coming in from a host of state agency systems, each of which operated differently. In even more practical terms, change orders started coming in almost immediately after the state contract was signed, and increased the cost of the project by approximately $40 \%$ over three years. From this, we learned the importance of involving cross-functional teams more extensively and earlier in the process so that when the final contract was executed, it reflected the realities on the ground.

A procurement process like MyFloridaMarketplace (MFMP or MyFlorida) follows a general set of principles. The process is controlled by state procurement or purchasing rules and regulations. These rules are different in every state but the approach is fundamentally similar everywhere. The rules are intended to provide a process for public officials to buy the goods and services that they need in order to do the things that public officials are asked to do; the process is intended to be fair and provide the best value in a way that is transparent to the general public. Fair means that the government does not show favoritism to any particular provider. Typically, government contracts are put out for bid in a public process that allows anyone to participate and demonstrate that their product or service meets government needs. Best value is a selection criterion that looks at price (or cost) but also looks at other characteristics of the companies that could be awarded the contract. Among those could be such things as past successful performance of the same sort of work for a different government entity (either in the same jurisdiction or another), past successful performance of different work for the government agency going out to bid on the current project, and the ability (and willingness) to service the contract. Each state has specific rules and regulations about the criteria for the contract award. Best value is used in some places instead of, or in addition to, lowest price. Finally, transparency means that the process is public. Requests for information and all the subsequent steps are advertised to the general public and award decisions are made in an open public forum.

The procurement process also proceeds generally in stages. As the first stage, a government office issues a request for information (RFI) about 
how to address a particular problem or how to implement a particular aspect of its work. The RFI is used to collect information from potential vendors about what is possible in the field. In this stage, a SME can play a key role in providing information about different options and solutions and in interpreting the information that vendors provide. Some jurisdictions and agencies put this preliminary information out into the field as a request for letters of interest or intent (LOI). The LOI are statements from interested vendors that present their particular methods for investigating an issue and developing a solution. The information gathered through the RFI and/or LOI is used to determine the scope of the project, the work that is expected, and the deadlines. The scope and specifications of the project refer to the jurisdiction and parameters of the work. Specifications define how the work is to be done, including designation of required and optional components and processes. The work that is expected includes delivery and installation of purchased items and services and other activities including training, support when problems occur, and planning documents such as timelines of plans to design, implement, and test the items that are being acquired. Deadlines include not only final deadlines for delivery, installation, or implementation but also interim deadlines including deadlines for testing critical features and critical stages of a process.

When the scope, general parameters, and deadlines have been determined, the information is presented to the public in the form of a request for proposals (RFP). The RFP is advertised to the general public, or may be presented only to a limited group of vendors who have been determined to be qualified to provide the goods or services. Sometimes these qualifications are determined through a request for qualifications (RFQ). Through these processes, potential vendors demonstrate their qualifications to meet the requirements of the proposal. An invitation to negotiate (ITN) or an invitation to bid may be extended to all interested firms, or to only a select group of vendors determined to be qualified.

Vendors are then recommended, perhaps in some sort of order by lowest price or best value, and perhaps an additional demonstration of performance ability is required. Selection is typically through a funding authority such as county commissioners or the state controlling board. Contracts are drawn up and implementation begins. Through my work on MyFlorida and other similar projects I gained experience with all of these aspects, and can share a few observations that can be useful for election officials. 


\section{Lessons About Procurement for Election Officials}

Election officials are involved with contracts for all sorts of hardware and software for voting systems and related products and services. And election officials know the end results that they want to achieve, the communications that they need in real time and otherwise between local and state offices, and the time frames that matter to their voters and their other stakeholders.

That said, gaps remain between what election officials need and what the procurement process generally provides. The technology of elections has changed significantly since the first wave of electronic voting systems were designed and implemented across the country after the Help America Vote Act (HAVA) of 2002, and election officials today may not feel prepared to buy new equipment, software, or related support services. Election officials are also familiar with the cost of changing technology, particularly software; as with all technology, the software that is used-whether for voter registration, casting ballots, or tabulation and reporting-has been frequently updated.

Election technology procurement also requires an orientation to a climate of constant change. Change over time is (and has been) inevitable in election technology. Hardware and software specifications change as new products are developed. As contracts are implemented, unexpected events occur and new needs are identified that may require additions (or change orders) to a contract. Election offices may also need to acquire technology in phases, due to limited funding overall, or due to limitations imposed by their local funding authorities. Over time, election officials and policy makers also adopt new methods of conducting elections that may also be linked to new technologies - or may be linked to technologies that are not linked to the policy change. All of these factors can result in a change in scope for an existing project or the need for a new project.

What this means is that more often than not, the process that I described will encompass change orders that increase the overall cost of the project. For example, a state may contract for a voter registration system that allows the registrar of voters to classify voter registrants as ineligible for a variety of reasons. But changes in state law may require that voter registrants be reclassified in a way that is not in the initial software. Or an ePollbook system may be designed, purchased, and implemented just before a state passes a law requiring voter identification, necessitating the addition of both software and hardware to allow for swiping government-issued IDs 
at sign-in. To further complicate matters, a state legislature could mandate a new method of voting or registration, such as early voting or same-day registration, and also not adopt a requirement that local jurisdictions use related technology (such as signature recognition). What this means is that the problems and solutions are not aligned, and the opportunities to procure solutions are also not aligned - and what seems to be the most complete or comprehensive solution may not actually be authorized by state law. And as with all government processes, the time needed for acquisition expands dramatically where approvals are needed from multiple boards or commissions, and from state offices.

Some changes are inevitable, of course, and are part of all government contracting. Regardless of the reason, changes are also expensive. The cost of change orders is more than simply the monetary increase in the overall amount of a contract. Change orders involve the time of vendor staff and this cost is passed along with the changes. Change orders also require public time and attention through implementation and administration.

MyFloridaMarketplace illustrates an extensive effort and coordination that will be true for other state-level procurements. The challenge for government officials is to design front-end acquisition requests and later decision-making processes that are fully informed to minimize these change orders. Change orders necessitated by changes in law are necessary evils, but change orders driven by lack of expertise on the part of government officials are another problem altogether. There is an information gap between procurement experts, election officials, and vendors about the content and operation of various election systems and their components.

This gap occurs for multiple reasons, and these reasons may overlap. It could be the case that incorrect or insufficient assumptions were made at the outset about what was needed or what could be provided, or both. Incorrect or insufficient information in an RFI or RFQ is then reinforced in the RFP; this gap is magnified with each subsequent step of the procurement process. Any gaps on the front end are also magnified after a contract has been signed, during the implementation phase. This information gap generates change orders, cost increases, and inefficiencies that should be avoided-and can result in a product or service that is not fully useful.

\section{Subject Matter Experts}

One way to address this issue is to rely more extensively on SMEs in the procurement process. This can be done by hiring staff or by hiring temporary SME assistance to help write proposals and responses throughout the 
procurement process. SMEs can also be called on to draft implementation plans for technology acquisitions. In short, SMEs are valuable all throughout the process including RFP solicitation and contract negotiation.

This can be done for the whole of a project or only for the most technical aspects. This may be too expensive for smaller local offices, but this could be a support that state offices provide. In thinking about the SME, it is important for election officials to consider how to develop an interactive and enduring relationship between the public office and the SMEs, and with the selected vendor(s).

Another effective method of gathering SME expertise is to contact national and state professional associations. In MyFlorida, we reached out to national associations such as the National Institute of Government Purchasing (NIGP) and the Florida Association of Public Procurement Officers (FAPPO), which is our state professional association for the field. What that helped us understand was how unique our project was; in other projects, these organizations had been a tremendous source of information. Here, however, we learned that other states had no best practice, no road map, and no lessons learned, and that was important in and of itself. These organizations offer training, information exchange, and certification such as Certified Public Procurement Officer (CPPO) and Certified Professional Public Buyer (CPPB). Even if hiring dedicated purchasing staff is not possible, these trainings and certifications and similar programs could be a cost-effective method of enhancing existing office capacity.

\section{Election Administrators with Special Expertise}

Another approach is to hire election administrators with more IT expertise or procurement expertise. IT in government is not as lucrative as in the private sector, and so this option may be more viable within state offices. By comparison, procurement expertise may be more affordable. Procurement expertise may also be valuable in developing both a realistic estimate of cost and a timeline for understanding the procurement process, which can involve many steps and feedback loops. A procurement specialist can assist in constructing contract provisions that will maintain strong relationships between the public office and its technology vendors.

\section{Interactive Vendor Relationships}

Vendor relationships are essential. Election officials at all levels should seek contract provisions that reinforce enduring relationships with technology 
vendors. The changing environment shows us that the information gap will only increase over time; vendors will always know about their technology and election officials will always know about the problems that they want to address. What the technology procurement system needs are ways to develop enduring relationships that share information while needs are identified, while vendors are selected, and after the contract has been signed.

Open Access This chapter is licensed under the terms of the Creative Commons Attribution 4.0 International License (http://creativecommons.org/licenses/ by $/ 4.0 /)$, which permits use, sharing, adaptation, distribution and reproduction in any medium or format, as long as you give appropriate credit to the original author(s) and the source, provide a link to the Creative Commons licence and indicate if changes were made.

The images or other third party material in this chapter are included in the chapter's Creative Commons licence, unless indicated otherwise in a credit line to the material. If material is not included in the chapter's Creative Commons licence and your intended use is not permitted by statutory regulation or exceeds the permitted use, you will need to obtain permission directly from the copyright holder.

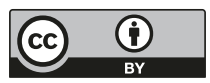

